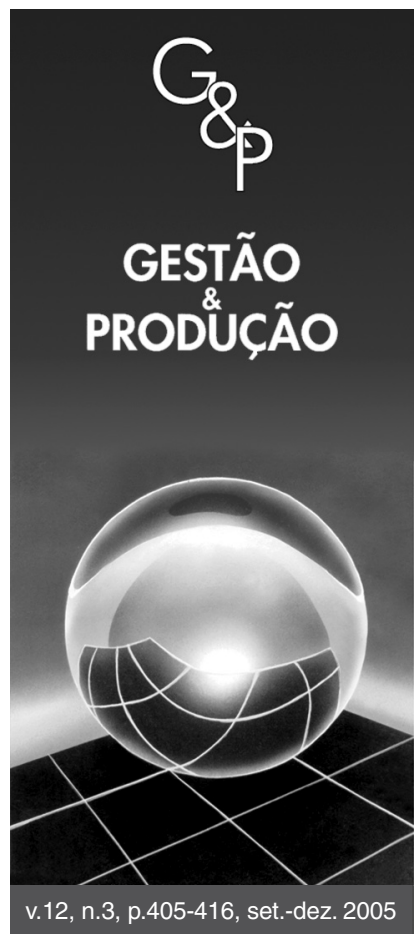

\title{
ESTRATÉGIAS DE SOBREVIVÊNCIA PARA PEQUENAS E MÉDIAS EMPRESAS EM AMBIENTES GLOBALIZADOS: UM ESTUDO DE CASO DO SETOR ELETROELETRÔNICO
}

\author{
Leila Keiko Canegusuco Jansen \\ Roberto Gilioli Rotondaro
}

Departamento de Engenharia de Produção, Escola Politécnica da Universidade de São Paulo, Av. Prof. Almeida Prado, 128, Tr.2, Biênio 2 , CEP 05508-900, São Paulo, SP, Brasil, e-mail: leila.jansen@poli.usp.br, roberto.rotondaro@poli.usp.br

José Ulisses Jansen

Instituto de Pesquisas Energéticas e Nucleares, Av. Prof. Lineu Prestes, 2242, CEP 05508-000, São Paulo, SP, Brasil, e-mail: nana021295@uol.com.br

Recebido em 01/7/2005

Aceito em 30/11/2005

Resumo

Com a globalização, crescem os niveis de rivalidade e pressão competitiva entre os concorrentes atuando nos mesmos mercados e áreas geográficas. Mesmo assim, as pequenas e médias empresas vêm se tornando participantes críticos nas economias nacionais e nos negócios mundiais. Mas pouco se sabe sobre quais estratégias de operações estas pequenas e médias empresas utilizam diante da globalização. No Brasil, com o aumento dos processos de fusões, aquisições que se articulam entre as organizações globais e empresas que atuam nacionalmente, aumentaram a turbulência e a incerteza nos mercados. As empresas que conseguem obter um bom conhecimento do ambiente em que se inserem podem tomar ações pró-ativas e influenciar na evolução do sistema. Este artigo trata da relação entre ambiente de competição, incertezas, ameaças e oportunidades percebidas, com foco em pequenas e médias empresas. É apresentado um estudo de caso de uma empresa de médio porte, denominada de X, que possuía uma situação estável no mercado por aproximadamente onze anos, ocupando a segunda posição, até que se deu a aquisição da empresa líder nacional pela líder global. O artigo apresenta as sugestões seguidas e que auxiliaram esta empresa a manter-se competitiva, embora carente de recursos financeiros e humanos.

Palavras-chave: pequenas e médias empresas, globalização, estratégia de operações, capital social.

\section{Introdução}

A Nova Economia Mundial combinou a crescente globalização, as tecnologias avançadas e novas formas de organização corporativa de modo a redefinir o papel do gerenciamento de operações. Cada um desses elementos já existia, mas o que tornou a Nova Economia Mundial diferente foram as novas formas dos três se entrelaçarem em arranjos complexos criando novos setores industriais e abordagens de negócios (Hayes et al., 2005).

$\mathrm{Na}$ velha economia, a unidade organizacional de análise era uma unidade de operação (uma fábrica, uma companhia, uma divisão, unidade de negócios); a maior responsabilidade dos gerentes de operações era controlar o fluxo de materiais (e/ou informações) por meio de uma sequiência de etapas de processo; a maior preocupação dos gerentes de operações era reduzir a variável custo de produção; e os concorrentes eram inimigos. Na Nova Economia Mundial, o papel da gestão de operações se expandiu para facilitar e estimular a produção e entrega de produtos compatíveis, reforçadores, por meio de uma organização virtual de parcerias e alianças dentro de um grupo móvel de empresas fornecedoras de produtos/serviços complementares e de concorrentes que, por vezes, cooperam entre si (Hayes et al., 2005).

Com a globalização, tornou-se uma tendência mundial a emergência de pequenas e médias empresas ativas internacionalmente. Mas, apesar dessas empresas estarem se tornando participantes críticos nas economias nacionais e nos negócios mundiais, até o momento, pouco se 
sabe a respeito de como elas operam e prosperam diante da globalização. Percebe-se que a complexidade das operações em ambientes globalizados é consideravelmente mais onerosa para as pequenas e médias empresas do que para as grandes empresas, e que o sucesso depende em grande parte da formulação e implementação de suas estratégias (Knight, 2000).

A Organisation for Economic Co-operation and Development (2000), na "The Bologna Charter on SME Policies", documento redigido em conjunto com vários países, inclusive o Brasil, cita que a globalização, a aceleração das mudanças tecnológicas e a inovação criam oportunidades para as pequenas e médias empresas, mas também envolvem custos e novos desafios. Recomenda que, ao se desenvolverem políticas para as pequenas e médias empresas, deva se considerar que a habilidade dessas empresas em gerenciar a inovação é melhorada pela facilidade em admitir e treinar pessoal qualificado, pela difusão e inovação da cultura, pela disseminação tecnológica, informação de mercado e assistência oferecida (por exemplo, por melhorias em mecanismos de mercado de trabalho, ligações entre empresas e sistemas de educação, e entre indústria e centros de pesquisa universitários).

No Brasil, o aumento das fusões e aquisições articuladas entre as organizações globais e empresas que atuam nacionalmente apresenta um ritmo mais acelerado, levando a reorganizações do mercado e aumento das incertezas. Este é um processo dinâmico que aumenta o nível de rivalidade entre os concorrentes que atuam no mesmo mercado e área geográfica e que afeta, de modo muito profundo, as pequenas e médias empresas.

A reação de cada organização às mudanças dependerá da sua capacidade de perceber a dinâmica dos movimentos, de avaliar suas implicações e escolher estratégias relevantes. Dependerá também e fortemente de como ela utiliza nas suas estratégias os diversos recursos críticos de que dispõe.

A obtenção de informações sobre vários aspectos específicos do setor, como clientes, competidores, fornecedores, facilita o alinhamento entre as estratégias de competição e os ambientes. A observação do ambiente informa a empresa de eventos e tendências que afetam sua sobrevivência e prosperidade (Beal, 2000).

Este trabalho apresenta um estudo de caso de uma empresa de médio porte, denominada de X, filial de uma multinacional, situada em Minas Gerais, que atua nacionalmente como tier two no setor eletroeletrônico. Durante aproximadamente onze anos, as posições de mercado da empresa X se mantiveram estáveis dentro do território nacional, sendo este dividido entre três concorrentes, até que, em 2003, a empresa líder foi adquirida pela líder global. Este fato relevante, acrescido da conjuntura eco- nômica nacional, fez com que a empresa revisse suas operações para se inserir no mercado global.

Diante de tal situação, podia-se prever que a rivalidade e pressões competitivas atingiriam patamares bem acima dos existentes. A empresa X elaborou então um trabalho no qual buscou analisar mais profundamente toda a situação e listar possíveis ações estratégicas para a manutenção de sua competitividade no mercado.

Na primeira fase do trabalho, foi adotada uma metodologia composta por elementos oriundos de teorias no campo das Organizações e Administração, apresentando o seguinte delineamento:

a) Mapeamento dos sistemas de pressão competitiva do ambiente;

b) Determinação do nível de incerteza;

c) Escolha de um modelo de estratégia competitiva;

d) Alinhamento da estratégia competitiva com as competências organizacionais; e

e) Apresentação de sugestões.

Este artigo tem como objetivo verificar como a situação da empresa X evoluiu no curso de um ano e avaliar se as sugestões oriundas da primeira fase do trabalho resultaram na manutenção da competitividade da empresa. $\mathrm{O}$ estudo deste caso é um exemplo de como as empresas de pequeno e médio porte operam diante da globalização.

\section{Conceitos básicos}

\subsection{Globalização}

A palavra globalização possui mais de um significado segundo diversos aspectos, como o sociológico, o econômico e o político. Houaiss (2004) define globalização na rubrica economia e política como sendo:

- "intercâmbio econômico e cultural entre diversos países, devido à informatização, ao desenvolvimento dos meios de comunicação e transporte, à ação neocolonialista de empresas transnacionais e à pressão política no sentido da abdicação de medidas protecionistas";

- "espécie de mercado financeiro mundial criado a partir da união dos mercados de diferentes países e da quebra das fronteiras entre esses mercados"; e

- "integração cada vez maior das empresas transnacionais, num contexto mundial de livre-comércio e de diminuição da presença do Estado, em que empresas podem operar simultaneamente em muitos países diferentes e explorar em vantagem própria as variações nas condições locais".

Conceitualmente, a globalização vista como estratégia das empresas globais foi foco de uma pesquisa de quatro anos de duração, encabeçada por Porter (1993). Esta pesquisa foi realizada em dez países considerados 
de destacado sucesso mundial e buscou identificar quais eram os atributos de uma nação que estimulavam a vantagem competitiva em um setor industrial de manufatura ou serviço.

Segundo Porter (1993), a competição em muitas indústrias (referindo-se a grupos de competidores que produzem mercadorias ou serviços que competem diretamente entre si) internacionalizou-se: as empresas competem com estratégias globais, as vendas atingem níveis mundiais, as compras de matéria-prima e componentes são feitas pelo mundo todo, as atividades são localizadas em diversas nações onde se encontram fatores de baixo custo, são formadas alianças com empresas de outros países para se ter acesso às vantagens desses outros locais. A melhoria dos transportes contribuiu para o intercâmbio dos fatores de uma nação para a outra. É frisado, porém, que são as empresas e não as nações que competem em mercados internacionais.

\subsection{Sistemas de pressão competitiva}

Os sistemas de pressões, segundo a definição de D’Aveni (2002), são complexos padrões de mudanças dos contatos que se sobrepõem entre empresas rivais que alteram continuamente o ambiente de um setor industrial mudando os incentivos para os concorrentes competirem, tolerarem-se mutuamente ou mesmo cooperarem formalmente entre si. Os sistemas de pressões diferem de setor para setor. Dentro de cada setor, as pressões são assimétricas, ou seja, a pressão que a empresa A exerce sobre B não é necessariamente a mesma que $\mathrm{B}$ exerce sobre $\mathrm{A}$, porque os mercados em que ambas competem diferem em importância nos portfólios de cada empresa.

Se a empresa possui um bom conhecimento do ambiente em que atua, com conhecimento a respeito dos seus competidores em determinado período, o mapeamento dos sistemas de pressão pode auxiliá-la a compreender como os concorrentes estão exercendo pressão uns sobre os outros nesse período. A empresa pode utilizar esse conhecimento para escolher seu comportamento definindo quem serão seus competidores, seus aliados e em quais mercados poderá atuar, podendo inclusive influenciar estrategicamente a evolução do setor em que atua.

O mapeamento dos sistemas de pressão competitiva é um desenho esquemático em que os concorrentes são representados por círculos de raios proporcionais às dimensões das empresas, alianças tácitas ou formais são desenhadas como linhas conectando as empresas que participam da aliança e as pressões são representadas por flechas com as pontas no sentido em que são feitas as pressões. As flechas são grossas e sólidas, quando as pressões são fortes, e finas e pontilhadas, se as pressões são amenas.

O propósito básico do mapeamento do sistema de pressões não é o de ilustrar as táticas de competição em uso, como guerras de preço, de propaganda ou de inovação, mas de revelar quais participantes têm potencial ou incentivos para promover ou impedir o uso futuro de pressões.

\subsection{Estratégias e incertezas}

Os processos de globalização fazem crescer as incertezas e estas devem ser consideradas com rigor pelas organizações. Quando as incertezas são subestimadas, as organizações se arriscam a estabelecer estratégias que possam não defendê-las das ameaças e que as impeçam de aproveitar as oportunidades.

Ambientes complexos e incertos fazem crescer a necessidade de uma forte postura estratégica nas organizações, especialmente nas pequenas e médias empresas, que carecem de recursos para competirem com as grandes rivais do seu próprio país e com as outras que vêm de fora (Knight, 2000).

Como as incertezas diferem entre si, é importante para as organizações tentarem responder a duas questões básicas: Qual o tempo de duração da incerteza? Quais as prováveis conseqüências? (Lane e Maxfield, 1995).

Courtney et al. (1997) sugerem classificar incertezas no âmbito das organizações segundo quatro níveis que crescem em complexidade seguindo a ordem seguinte:

- Futuro claro o suficiente. Quando previsões precisas podem determinar a estratégia. Ex.: estratégia contra baixos preços de um novo concorrente;

- Futuros alternativos. Alguns resultados discretos podem definir o futuro. Ex.: estratégias de capacidades para plantas químicas, desregulamentações de mercados;

- Range de futuros. Range de possíveis resultados, mas em cenários não naturais. Ex.: entrada em mercados emergentes, desenvolvimento de tecnologias emergentes; e

- Verdadeira ambigüidade. Nenhuma base de previsão do futuro. Ex.: entrada em mercado de consumo de aplicações multimídia.

A identificação do nível de incerteza permitirá à organização utilizar ferramentas de análise apropriadas para formular a melhor estratégia para cada situação. Um rol de ferramentas analíticas encontra-se disponível e podem ser utilizadas em cada caso, segundo o nível de incerteza do ambiente: cobrem desde as tradicionais, usadas em estratégia corporativa, passando por teoria de decisão, teoria dos jogos, planejamento de cenários e chegando aos modelos dinâmicos, entre outras.

É interessante notar que no quarto nível de incerteza, da verdadeira ambigüidade, as situações são de alta complexidade, beirando ao caos. O estudo desse tipo de situação tem aumentado ultimamente. 


\subsection{Estratégia competitiva}

Muito se tem discutido a respeito das fontes de vantagem competitiva que as empresas têm utilizado. Conforme Fleury e Fleury (2003), essas discussões convergem para três linhas básicas de pensamento:

- O posicionamento estratégico, tendo Porter como seu maior protagonista, que foca mercados e competidores e as vantagens competitivas advindas da identificação de ameaças e oportunidades;

- O RBV (Resource Based View), popularizado por Hamel e Prahalad, que considera que toda empresa tem um portfólio baseado em recursos físicos, financeiros, marca, imagem, sistemas administrativos, cultura organizacional e recursos humanos, que criam vantagem competitiva; $\mathrm{e}$

- A abordagem originária da Wharton Business School que insere a idéia de dinamismo, na qual a estratégia cresce em dinâmica e complexidade e a hipercompetição, ou seja, a competição acelerada, não permite esperar que o competidor se mova para decidir reagir.

Fleury e Fleury (2003) sugerem a seguinte abordagem, que foi a assumida na primeira fase do trabalho realizada em 2004, que combina a formulação da estratégia, aprendizado e construção da competência em um modelo dinâmico, conforme representado na Figura 1. O processo de construção da competência deve ser desenhado para suportar e melhorar as estratégias competitivas da empresa. Simultaneamente, as competências organizacionais são componentes intrínsecos do processo de formulação da estratégia, pois o posicionamento estratégico deve considerar a alavancagem ou impedimentos potenciais de suas competências. Por fim, o aprendizado organizacional é o processo que dá dinamismo ao ciclo.

\subsection{Alinhamento de estratégias competiti- vas e competências organizacionais}

Em Fleury e Fleury (2003), é assumido que há três estratégias distintas por meio das quais as empresas competem nos mercados:

- Excelência operacional: empresas que possuem esta estratégia têm como objetivo oferecer produtos que otimizam a relação qualidade/preço. Ex.: Ford, Toyota, Compaq, Dell;
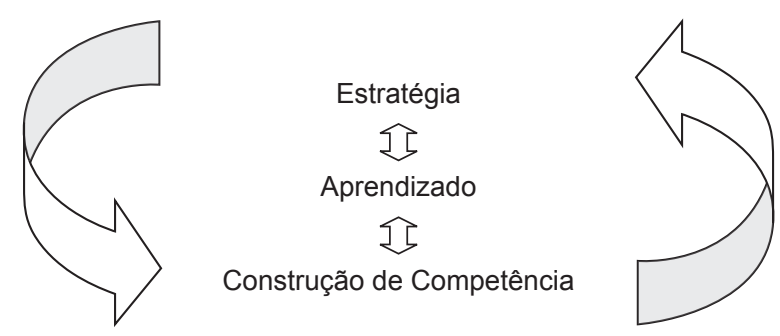

Figura 1. Ciclo Estratégia-Competência. Fonte: Fleury e Fleury (2003).
- Inovação de produto: neste caso as empresas garantem seu sucesso econômico lançando sistematicamente novos produtos radicais no mercado. Ex.: Intel, Nike, $3 \mathrm{M} ; \mathrm{e}$

- Dirigida pelo cliente: empresas que atendem clientes específicos em áreas específicas, customizando produtos e serviços para atender às necessidades dos clientes. Ex.: Caterpillar.

Para cada estratégia escolhida, há uma competência essencial que melhor se alinha, cabendo às outras reforçá-la, conforme apresentado na Tabela 1.

Ao longo da cadeia de valor, deve-se procurar um arranjo de competências que faça evoluir o desempenho da cadeia como um todo. Para empresas que adotam como estratégia competitiva a excelência operacional, Fleury e Fleury (2003) sugerem a distribuição de competências ao longo da cadeia tal qual a existente na indústria automobilística, apresentada na Tabela 2.

\subsection{0 capital social na construção da competência}

A complexidade e incerteza dos ambientes competitivos neste século XXI estão requerendo um novo tipo de liderança nas organizações: a liderança envolvida com a construção de recursos e competências intangíveis, como o capital humano e o capital social. O capital humano é o repositório de conhecimentos, habilidades e capacidades da organização; o capital social provê acesso aos recursos críticos. Ambos contribuem significativamente para o alcance de vantagem competitiva (Hitt e Ireland, 2002).

O capital social envolve as relações entre indivíduos e organizações que facilitam ações e criam valor. Ele pode ser interno ou externo à organização. O conceito de capital social interno refere-se aos relacionamentos entre os líderes estratégicos e seus liderados e aos relacionamentos em toda a organização.

O capital social externo refere-se aos relacionamentos formais ou informais estabelecidos com agentes externos à organização, como clientes, fornecedores, concorrentes, consultores, especialistas, enfim, entre todos os elementos que propiciam conhecimentos e informações. Como conhecimento organizacional, entende-se qualquer informação, crença ou capacitação que a organização possa aplicar às suas atividades (Anand et al., 2002).

Pelo modelo de busca de competitividade adotado neste trabalho, representado na Figura 1, o ciclo estratégia-competência torna-se dinâmico pelo aprendizado organizacional. O aprendizado eleva o nível de conhecimento nas atividades críticas da organização. Mas as fontes para este aprendizado encontram-se, para uma grande parte de empresas, principalmente para as empresas pequenas e de médio porte, fora de suas fronteiras, por vários motivos, tais como o limitado contingente hu- 
mano resultado dos muitos processos de reengenharias e enxugamentos que as empresas vêm sofrendo e pela evolução constante do conhecimento.

A empresa que opta pelo aproveitamento do seu capital social deve inicialmente identificar o tipo de conhecimento de que necessita, se explícito (facilmente comunicado, redigido e compartilhado) ou tácito (difícil de ser comunicado), e o volume do conhecimento necessário, se alto ou baixo. Para cada par formado pelo tipo e volume de conhecimento necessário, são sugeridas algumas maneiras apropriadas de aproveitamento desse recurso. $\mathrm{Na}$ Figura 2, são apresentados alguns desses métodos.
Alguns cuidados devem ser tomados para que haja um bom aproveitamento do capital social como: preparar a organização de modo que tenha um nível adequado de conhecimento prévio com boa capacidade de absorção; e atentar para o risco de que os relacionamentos possam se transformar em sujeição.

\section{Estudo de caso da empresa X - primeira fase}

A empresa X está sediada em Minas Gerais. Ela faz parte de uma organização multinacional que opera duas

Tabela 1. Tipos de estratégias e competências (competências mostradas em negrito deveriam ser as competências essenciais para cada estratégia). Fonte: Fleury e Fleury (2003).

\begin{tabular}{llll}
\hline Estratégia competitiva & \multicolumn{1}{c}{ Operações/Manufatura } & $\begin{array}{c}\text { Desenvolvimento de } \\
\text { produto }\end{array}$ & \multicolumn{1}{c}{ Vendas e marketing } \\
\hline Excelência operacional & Produção “Lean” & $\begin{array}{l}\text { Inovações incrementais } \\
\text { produção inicial }\end{array}$ & $\begin{array}{l}\text { Convencer o mercado da relação } \\
\text { ótima de preço/qualidade }\end{array}$ \\
\hline Inovação de produto & Manufatura ágil & $\begin{array}{l}\text { Inovações radicais } \\
\text { (breakthrough) }\end{array}$ & $\begin{array}{l}\text { Preparar o mercado e educar } \\
\text { clientes potenciais }\end{array}$ \\
\hline Dirigida pelo cliente & $\begin{array}{l}\text { Desenvolvimento de soluções } \\
\text { específicas }\end{array}$ & $\begin{array}{l}\text { Desenvolver relacionamentos } \\
\text { muito próximos com clientes espe- } \\
\text { cíficos para entender necessidades } \\
\text { atuais e futuras }\end{array}$ \\
\hline
\end{tabular}

Tabela 2. Distribuição da competência pelos diferentes tiers de uma cadeia - excelência operacional. Fonte: adaptado de Fleury e Fleury (2003).

\begin{tabular}{cccc}
\hline Posição na cadeia & $\begin{array}{c}\text { Competência em } \\
\text { operações }\end{array}$ & $\begin{array}{c}\text { Competência em } \\
\text { desenvolvimento de } \\
\text { produtos }\end{array}$ & $\begin{array}{c}\text { Competência em vendas } \\
\text { e marketing }\end{array}$ \\
\hline Líder & CORE & $\begin{array}{l}\text { Desenvolvimento integral dos } \\
\text { produtos (incremental) }\end{array}$ & $\begin{array}{l}\text { Convencer o mercado da relação ótima } \\
\text { de preço/qualidade }\end{array}$ \\
\hline "First Tier" & Manufatura ágil & Desenvolvimento de sistemas & $\begin{array}{l}\text { Desenvolver relacionamentos muito } \\
\text { próximos com clientes específicos para } \\
\text { entender necessidades atuais e futuras }\end{array}$ \\
\hline "Second Tier" & Manufatura ágil & Desenvolvimento de componentes & $\begin{array}{l}\text { Desenvolver relacionamentos muito } \\
\text { próximos com clientes específicos para } \\
\text { entender necessidades atuais e futuras }\end{array}$ \\
\hline
\end{tabular}

\begin{tabular}{|c|l|l|l|}
\hline $\begin{array}{c}\text { Volume de } \\
\text { conhecimento } \\
\text { necessário }\end{array}$ & Alto & $\begin{array}{l}\text { Intercâmbio eletrônico de informações } \\
\text { entre as organizações (EDI, XML) } \\
\text { Ex.: Relatórios, pesquisas de mercado, etc. }\end{array}$ & $\begin{array}{l}\text { Alianças estratégicas } \\
\text { Ex.: Experiência para projetar, produzir, } \\
\text { promover produtos em outro país; } \\
\text { desenvolver tecnologia revolucionária, etc. }\end{array}$ \\
\cline { 2 - 4 } & Baixo & $\begin{array}{l}\text { Contatos sociais informais (telefone, e-mail) } \\
\text { Ex.: Volume de vendas do mercado, } \\
\text { novas promoções de vendas, etc. }\end{array}$ & $\begin{array}{l}\text { Aproveitamento dos parceiros, equipes inter- } \\
\text { organizacionais, consultores especialistas } \\
\text { Ex.: Reação do governo a fusões de grandes } \\
\text { empresas, opiniões legais, etc. }\end{array}$ \\
\hline \multicolumn{2}{|c|}{ Tipo de conhecimento } & Explícito & Tácito \\
\hline
\end{tabular}

Figura 2. Métodos apropriados para o aproveitamento do capital social. Fonte: adaptado de Anand et al. (2002). 
plantas na mesma área industrial. A primeira planta atua como tier one e a empresa X opera como tier two do setor eletroeletrônico. Durante onze anos o mercado em que atua, que sobrepunha produtos similares e áreas geográficas, foi praticamente dividido entre as três maiores concorrentes. A empresa $\mathrm{X}$ ocupa a segunda posição neste mercado.

Um fato novo se deu com a aquisição da líder do mercado nacional pela líder mundial em meados de 2003, desestabilizando o ambiente pelo acentuado aumento de poder da nova líder. Isso obrigou o corpo diretivo e gerencial da empresa $X$ a reavaliar suas estratégias. É importante salientar que a líder mundial atua também em outros mercados e este mercado em discussão representa $20 \%$ de suas operações.

Um indicador de competitividade, a participação no mercado antes e depois da aquisição da empresa líder, está apresentado na Tabela 3.

Quanto ao volume das operações, a partir da aquisição pode-se estimá-lo de acordo com a Tabela 4.

Os números que indicam as operações em nível mundial indicam como o desequilíbrio de forças se acirrou com a aquisição da líder nacional pela líder mundial.

A fim de aprofundar o entendimento das implicações dessa relevante mudança no mercado, a empresa $\mathrm{X}$ realizou o estudo aqui apresentado.

\section{Metodologia}

$O$ trabalho realizado na empresa $X$ foi baseado em entrevistas dos autores do artigo com o corpo diretivo da empresa. A duração do trabalho foi de três meses. Os dados utilizados foram dados primários fornecidos pela própria empresa.

A metodologia adotada para delinear o problema constou de cinco passos: a) Mapeamento dos sistemas de pressão competitiva do ambiente:

O interesse de mapear o sistema de pressões do ambiente adveio da necessidade da empresa $\mathrm{X}$ de administrar as pressões a que estava sujeita. A realização deste mapeamento só foi possível devido ao fato de a direção da empresa possuir um bom conhecimento do ambiente em que atua. Com o mapeamento puderam ser observados dois importantes aspectos: como o sistema de pressões se apresentou após a aquisição da líder nacional pela líder mundial e quais eram os comportamentos competitivos ou cooperativos que existiam naquele momento entre os concorrentes;

b) Identificação do nível de incerteza:

O mapeamento do sistema de pressões deu uma indicação da situação em que se encontrava a empresa $X$, mas o que dizer a respeito da incerteza do seu futuro? Esta incerteza era clara o suficiente para definir um portfólio de ações estratégicas ou era mais complexa que isso? Nessa etapa da metodologia tratou-se de identificar o correto nível de incerteza do futuro que pode ser antevisto pela empresa $X$;

c) Escolha de um modelo de estratégia competitiva:

Nessa etapa se procurou explorar se havia uma postura estratégica clara na empresa $X$ para se confirmar se a adoção do modelo dinâmico do Ciclo Estratégia-Competência era adequada;

d) Alinhamento da estratégia competitiva com as competências organizacionais:

Nesta etapa, foi avaliado se, nesse mercado que estava sendo considerado, a empresa X competia por excelência operacional, por inovação de produtos ou por postura dirigida pelo cliente. Verificou-se como se prepararia o alinhamento do desenvolvimento das competências com a sua estratégia competitiva; $\mathrm{e}$

Tabela 3. Participação no mercado nacional e mundial. Fonte: empresa X.

\begin{tabular}{lccccc}
\hline $\begin{array}{c}\text { Participação no mercado } \\
\text { antes da aquisição (\%) }\end{array}$ & $\begin{array}{c}\text { Líder } \\
\text { Nacional }\end{array}$ & Empresa X & Empresa Y & $\begin{array}{c}\text { Líder } \\
\text { Mundial }\end{array}$ & Outros \\
\hline Mercado Nacional & 55 & 25 & 15 & 5 & 0 \\
Mercado Mundial & 10 & 1 & 0 & 50 & 39 \\
\hline Participação no mercado depois & Líder & Empresa X & Empresa Y & Líder & Outros \\
da aquisição (\%) & Nacional & & & Mundial & \\
\hline Mercado Nacional & - & 25 & 15 & 60 & 0 \\
Mercado Mundial & - & 1 & 0 & 60 & 39 \\
\hline
\end{tabular}

Tabela 4. Volume e faturamento em nível mundial. Fonte: empresa X.

\begin{tabular}{lccccl}
\hline & Líder Nacional & Empresa $\mathbf{X}$ & Empresa Y & Líder Mundial & \multicolumn{1}{c}{ Outros } \\
\hline Relação de volumes (ton) & - & 1 & 1 & 200 & 130 \\
Faturamento (milhões US\$/ano) & - & 3 & 3 & 300 & Não estimado \\
\hline
\end{tabular}


e) Apresentação de sugestões.

Os resultados obtidos em cada uma das etapas levaram a um conjunto de sugestões fornecido à empresa $\mathrm{X}$. Esta etapa consolida estas sugestões.

\section{Resultados obtidos}

\section{a) Mapeamento dos sistemas de pressão competitiva do ambiente}

Conforme o método utilizado permite, foram utilizados os valores de relação de faturamento apresentados na Tabela 4 para a elaboração do mapa de pressões. $\mathrm{O}$ resultado do esquema está apresentado na Figura 3.

Pela observação do mapa do sistema de pressões, alguns pontos puderam ser evidenciados:

1. Observação do comportamento do líder:

- Existia um líder de mercado facilmente identificável. Esta empresa é uma multinacional de grande porte, com atividades de volume equivalentes nos continentes americano, europeu e asiático, atuando em outros mercados fora este em que compete com a empresa $\mathrm{X}$; e

- O líder pressionava assimetricamente as empresas menores. Na ocasião ainda não havia se estabelecido na América do Sul uma pressão similar a que ele efetuava localmente sobre suas concorrentes nos continentes europeu e norte-americano. Em todos os continentes, as concorrentes pressionadas respondiam a esta ação do líder, porém com intensidade inferior a que recebiam.

2. Observação dos subsistemas (foram considerados subsistemas grupos formais de empresas pertencentes à mesma organização, como matriz e filiais ou que mantinham alianças estratégicas) que influenciavam comportamentos:

- Existiam cinco subsistemas distintos nesse mercado, sendo o maior deles o do próprio líder;

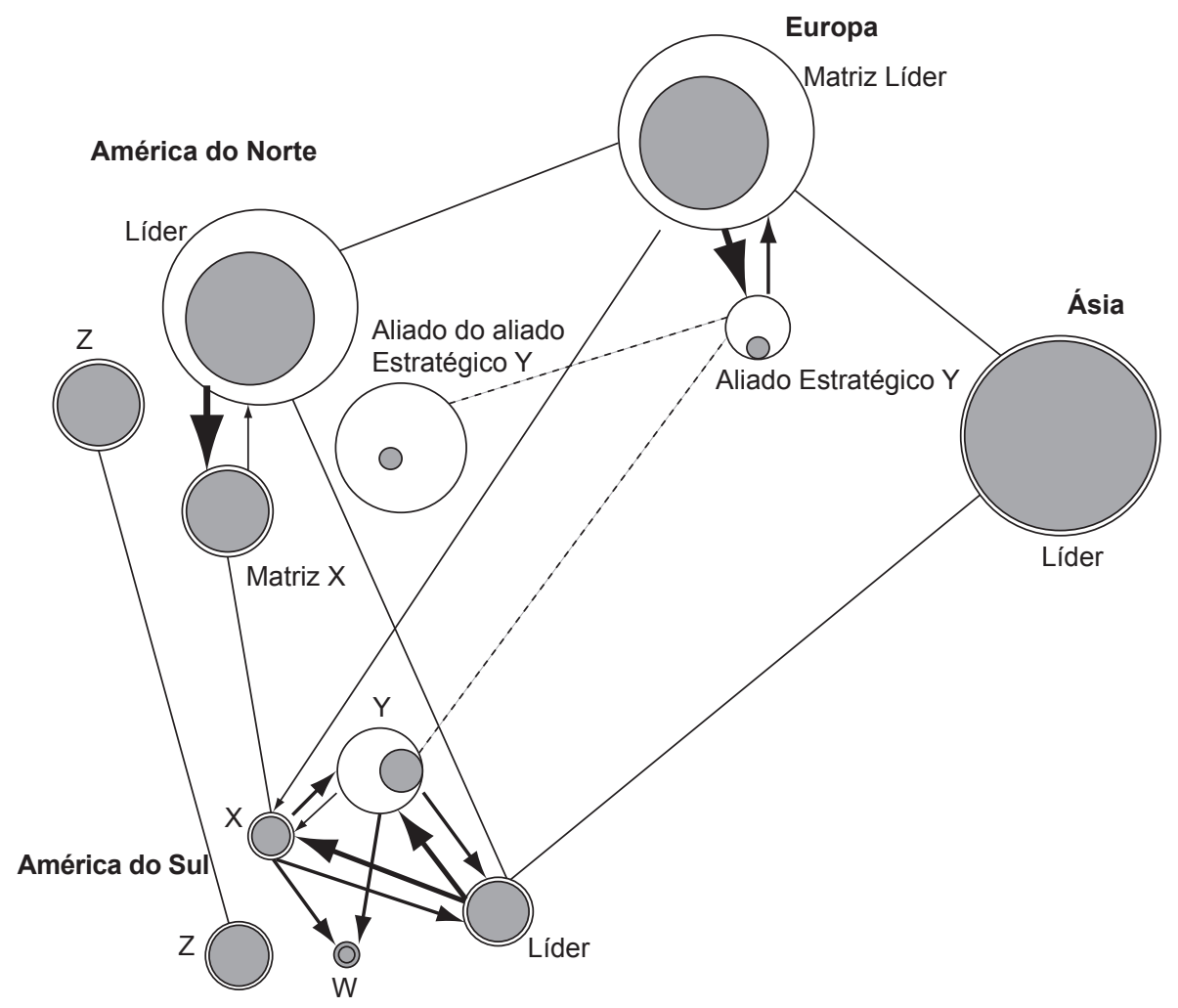

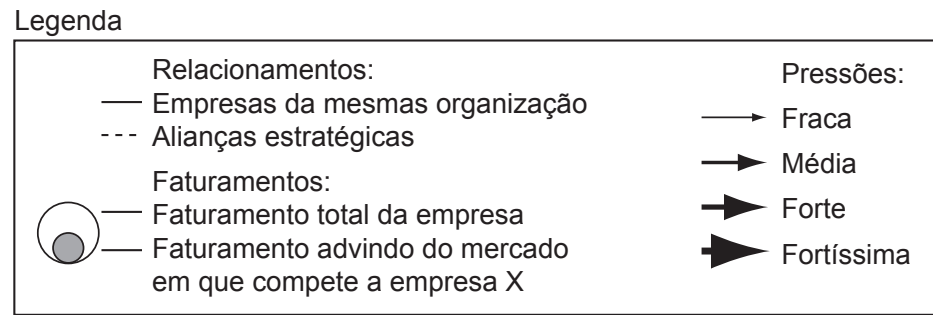

Figura 3. Mapa do sistema de pressões do ambiente da Empresa X. 
- Havia um subsistema diferenciado que não participava do jogo de pressões, pois não atuava no mercado. Tratava-se de empresas verticalizadas que produziam para consumo próprio (empresas Z);

- Havia um subsistema que se constituía por alianças estratégicas entre duplas de empresas independentes e com core business distintos (empresa Y e seu aliado; aliado de $\mathrm{Y}$ e seu aliado);

- Havia dois subsistemas compostos por matriz e filiais, o do líder e o da empresa X; e

- Havia um subsistema formado por uma empresa que trabalhava isoladamente.

\section{b) Identificação do nível de incerteza}

Considerando as definições para cada nível de incerteza, observou-se que a situação delineada no trabalho pôde ser classificada como sendo de incerteza do segundo nível, ou seja, a de Futuros Alternativos.

A estratégia implícita do líder parecia ser a de enfraquecer as empresas menores para posterior controle individual de preços. Sabe-se que ele tinha potencial para fazê-lo por vários meios distintos: redução de preços, inovação tecnológica, presença agressiva no mercado e serviços agregados.

Não se conhecia a priori a intensidade ou a conjugação dentre essas alternativas acima apontadas que seriam aplicadas e tampouco quando se dariam. Imaginava-se apenas que a primeira pressão conteria elementos que dissessem respeito à inovação tecnológica e serviços agregados, visto que estas estratégias já eram de certo modo divulgadas pelo líder.

\section{c) Escolha de um modelo de estratégia competitiva}

O modelo estratégico inicialmente imaginado, usando o ciclo dinâmico da Estratégia-Competência, demonstrou ser adequado à postura da empresa X. A sua postura se identificava como de adaptação ao futuro (Courtney, et al. 1997), ou seja, a empresa $\mathrm{X}$ buscava ganhar em seu mercado por meio de velocidade, agilidade e flexibilidade.

Procurar um nivelamento de recursos físicos e financeiros com a empresa líder não seria uma alternativa viável face ao aporte de capital necessário. Também não se poderia confiar em que os recursos e capacitações existentes internamente pudessem fazer frente ao embate que se vislumbrava.

É certo que a empresa $\mathrm{X}$ deveria desenvolver a curto e médio prazo as suas competências.

\section{d) Alinhamento da estratégia competitiva com as competências organizacionais}

A empresa $X$ participa de uma cadeia de valor bem definida no setor eletroeletrônico (tier two -> tier one -> cliente) em que o cliente final trabalha dentro do modelo de excelência operacional. Como já apresentado no item 2.4, seria imprescindível que a empresa $\mathrm{X}$ desenvolvesse suas competências essenciais e de suporte de modo alinhado à sua estratégia competitiva, o que significava elaborar um plano de amplo espectro abrangendo seus pontos fracos nas três linhas de frente, ou seja, na relação com o cliente, na manufatura e no desenvolvimento de componentes.

\section{e) Apresentação de sugestões}

- O que fazer

Diante das análises e resultados obtidos nas etapas da metodologia, algumas sugestões de ações a implementar puderam ser fornecidas à empresa $\mathrm{X}$. As principais delas estão relatadas a seguir:

1. Transformar o tier one da sua cadeia de valor, que também pertence à mesma organização em seu guarda-chuva (D'Aveni, 2002) no território nacional, ou seja, um parceiro que previne a pressão sobre a empresa. Essa ação poderia se efetivar se o tier one consumisse preferencialmente produtos da empresa X. Para tanto, a empresa X deveria elevar rapidamente as suas competências essenciais que se encontram no campo do desenvolvimento de relacionamentos muito próximos com este seu cliente para entender suas necessidades atuais e futuras;

2. Da mesma forma, como na sugestão anterior, transformar a matriz da empresa $\mathrm{X}$ em seu guarda-chuva no mercado externo, fora do país. O comprometimento no desenvolvimento das competências segue a mesma linha;

3. Desenvolver suas competências de apoio, tanto nos produtos quanto nos processos, para nivelar-se ao líder no que tange à capacidade de inovação tecnológica e de serviços agregados;

4. Reduzir custos de matérias-primas por compras globais, dado que o líder já o fazia, e assim prevenir-se do enfraquecimento pelo lado de custos industriais; e

5. Analisar a aplicação de um comportamento colaborador com a empresa $\mathrm{W}$ que atuava isoladamente no mercado.

\section{- Como fazer}

Uma boa parte das ações listadas no item anterior (de 1 a 3) dizia respeito a aumentar o nível de competências da empresa X. Mas este aumento dificilmente seria efetivado se ela tivesse que contar apenas com os recursos existentes internamente às suas fronteiras. Neste caso, um bom catalisador desse processo seria o desenvolvimento do seu capital social.

\section{- Desenvolvendo o capital social na empresa X}

O capital social é um meio básico pelo qual se pode importar conhecimento externo para dentro da em- 
presa. Mas, para que ele possa ser bem aproveitado, alguns pontos devem ser compreendidos pelo corpo gerencial, conforme citados em Anand, Glicz e Manz (2002):

1. Os gerentes devem reconhecer e compreender seu papel no ambiente atual - que é de enfrentamento da crescente densidade de conhecimento - para suas tomadas de decisão;

2. Os conhecimentos e experiências passadas são menos úteis hoje, visto que as situações são novas e inesperadas; $\mathrm{e}$

3. Antes de importar conhecimento externo, a empresa deve desenvolver um nível adequado de conhecimento prévio para poder absorvê-lo.

Foi fornecida à empresa $\mathrm{X}$ uma sugestão de provedores externos de conhecimento. Os principais pontos estão apresentados na Figura 4.

\section{- Gerenciando o capital social na empresa X}

Um ponto-chave para que a empresa $\mathrm{X}$ usufruísse do capital social seria saber como administrá-lo. A administração do capital social implica nas seguintes ações:

1. Avaliação do estoque de recursos externos. Deve ser realizado um mapeamento contínuo dos seus vínculos com os provedores externos de conhecimento;

2. Desenvolvimento da capacidade de absorção do conhecimento do seu pessoal interno. $\mathrm{O}$ treinamento do próprio pessoal não deve ser interrompido;

3. Substituição do estoque de recursos. A informação obtida externamente de um provedor pode se tornar obsoleta sendo necessária a sua substituição; e

4. Configuração e alavancagem de recursos. Estar atento para as necessidades futuras de provisão externa de conhecimento e procurar onde obtê-las.

\section{Situação atual da empresa $X$ decorrido um ano - Segunda fase}

\section{a) Mapeamento dos sistemas de pressão competitiva do ambiente}

No período de um ano, algumas mudanças importantes no ambiente de competição da empresa $\mathrm{X}$ aconteceram, trazendo consequiências para sua estratégia de operação. A principal mudança foi a aliança estratégica firmada entre a matriz da empresa $X$ e a empresa líder na América do Norte. O mapa de pressões após essa alteração está apresentado na Figura 5.

O que se verifica é que não existe mais na América do Norte a pressão fortíssima da empresa líder sobre a matriz de X. Conseqüentemente, na América do Sul, a forte pressão que a líder exercia sobre a empresa $X$ foi suavizada. Se por um lado essa mudança trouxe benefícios para a empresa $\mathrm{X}$, pois ela passou a não se sentir tão ameaçada, por outro lado houve um perceptível bloqueio no fluxo de informações técnicas entre a empresa $\mathrm{X}$ e sua matriz.

\section{b) Identificação do nível de incerteza}

Em face da atual situação, o nível de incerteza para a empresa $X$ aumentou, mas continua sendo classificada como de segundo nível, ou seja, de Futuros Alternativos.

Em 2004, a estratégia implícita do líder parecia ser a de enfraquecer as empresas menores para posterior controle individual de preços e sabia-se que ela tinha potencial para fazê-lo pela redução de preços, inovação tecnológica, presença agressiva no mercado e serviços agregados.

Um fator que há um ano atrás não era considerado crítico, mas agora passou a sê-lo, foi o freqüente desabastecimento de matérias-primas essenciais vindas de fornecedores da China. A empresa líder, pelo fato de estar operando também na Ásia, encontra-se em melhor posição para desenvolver novos fornecedores, o que aumenta mais ainda as possibilidades de controle de preços no mercado.

\begin{tabular}{|c|c|c|c|}
\hline \multirow{2}{*}{$\begin{array}{c}\text { Volume de } \\
\text { conhecimento } \\
\text { necessário }\end{array}$} & Alto & $\begin{array}{l}\text { Informações divulgadas obtidas } \\
\text { pela sua matriz. } \\
\text { Ex.: pesquisas em bancos de patentes, grupos } \\
\text { de trabalho virtuais via intranet para novas } \\
\text { tecnologias. }\end{array}$ & $\begin{array}{l}\text { Alianças estratégicas com universidades e } \\
\text { laboratórios locais } \\
\text { Ex.: Busca de conhecimento tecnológico } \\
\text { de ponta. }\end{array}$ \\
\hline & Baixo & $\begin{array}{l}\text { Contatos sociais informais (telefone, e-mail, } \\
\text { reuniões, visitas) } \\
\text { Ex.: Volume de vendas do mercado, } \\
\text { novas promoções de vendas, lançamentos etc. }\end{array}$ & $\begin{array}{l}\text { Aproveitamento do tier one, matriz, equipes } \\
\text { interorganizacionais, consultores, especia- } \\
\text { listas, fornecedores, cliente } \\
\text { Ex.: Desenvolvimento dos componentes, inovação } \\
\text { tecnológica, desenvolvimento de serviços. }\end{array}$ \\
\hline \multicolumn{2}{|c|}{ Tipo de conhecimento } & Explícito & Tácito \\
\hline
\end{tabular}

Figura 4. Métodos sugeridos para o aproveitamento do capital social da empresa $X$. 


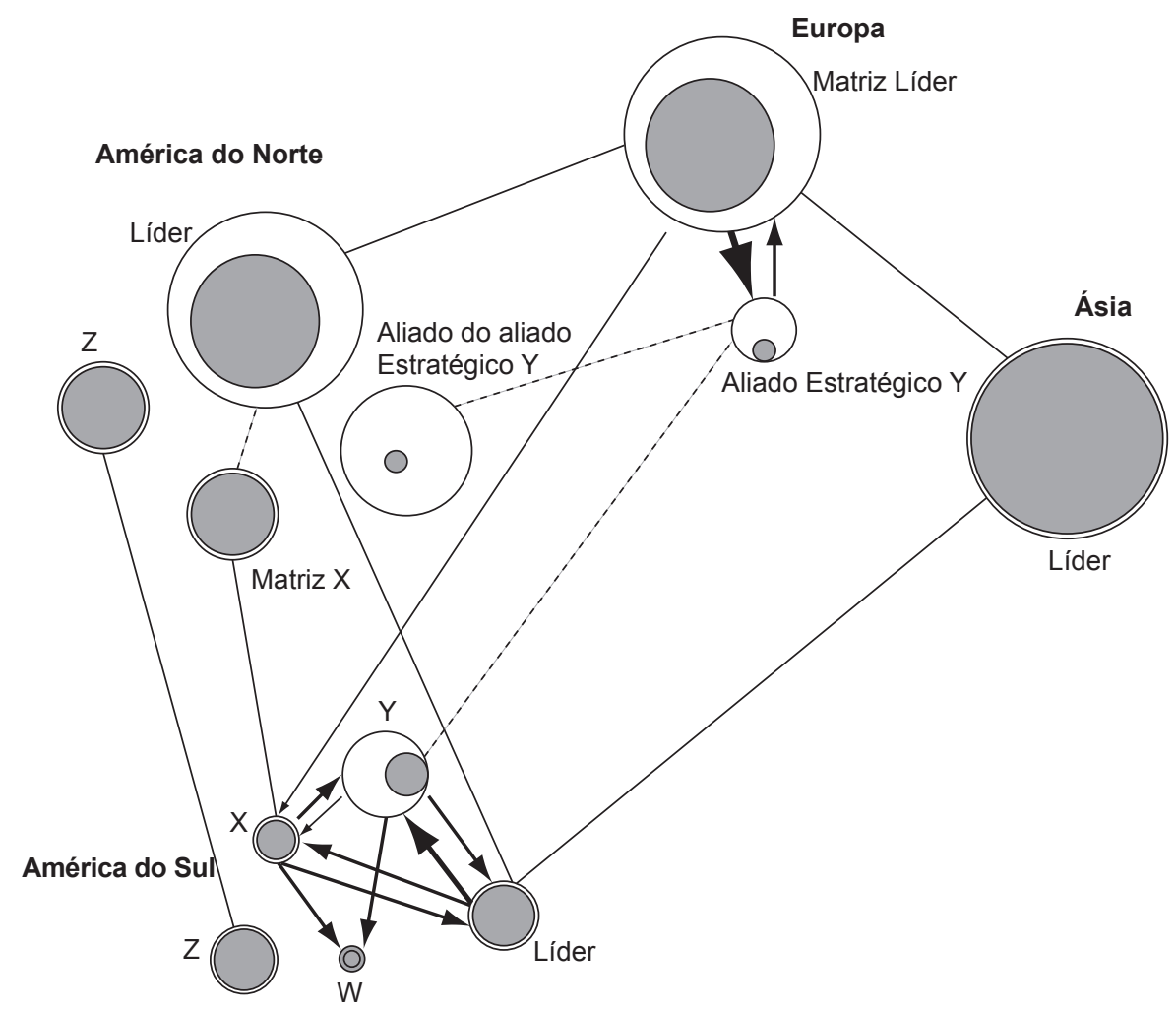

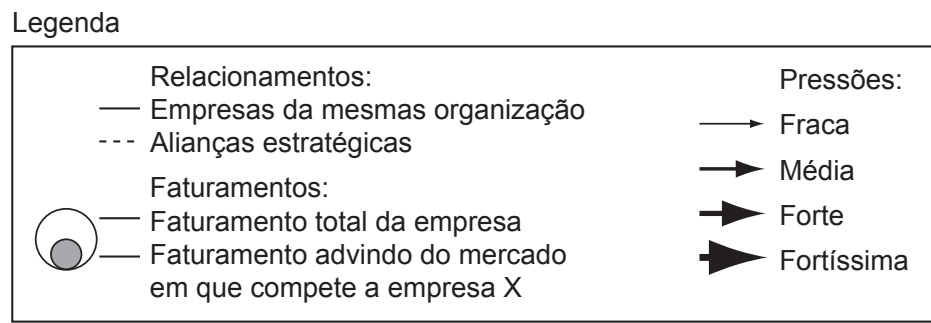

Figura 5. Mapa do sistema de pressões do ambiente da Empresa $X$ - após um ano.

\section{c) Escolha de um modelo de estratégia competitiva}

Quanto ao fato de a empresa X procurar ganhar em seu mercado por meio de velocidade, agilidade e flexibilidade, pode-se dizer que as melhorias nestes aspectos não foram significativas.

\section{d) Alinhamento da estratégia competitiva com as competências organizacionais}

A empresa $X$ procurou desenvolver suas competências essenciais e de suporte de modo alinhado à sua estratégia competitiva.

\section{e) Sugestões seguidas}

A sugestão para a empresa $\mathrm{X}$ desenvolver suas competências de apoio, tanto nos produtos quanto nos processos, para nivelar-se ao líder em capacidade de inovação tecnológica e de serviços agregados foi aceita, utilizando-se de recursos internos e externos. Como resultado dessa ação, foi possível transformar o tier one da cadeia (que também pertence à mesma organização) em guarda-chuva da empresa X no território nacional. Hoje o tier one consome $100 \%$ dos produtos da empresa $\mathrm{X}$ com ganhos de qualidade e logística.

Quanto ao gerenciamento do capital social, foram feitos novos vínculos com provedores externos de conhecimento de tecnologia e de produtos.

\section{Conclusões}

O artigo apresentou uma avaliação longitudinal de estratégia de operação de uma empresa de porte médio, que conta com escassos recursos financeiros para competir em um mercado amplamente globalizado.

Foi apresentada a situação entre 2003-2004 e os resultados de um trabalho para a elaboração de sua estratégia 
competitiva. Em seguida, novos dados foram inseridos demonstrando a evolução da situação.

A observação da dinâmica do ambiente após um ano de um modo mais formal, visto que no dia-a-dia os responsáveis procuram fazê-la, mostrou-se útil, pois alimentou a empresa $X$ de informações atualizadas, permitiu verificar a acurácia das informações e auxiliou a manutenção do modelo de estratégia-competência adotado.

Uma limitação do método de mapeamento de pressões utilizado é que ele fornece uma visão instantânea do ambiente e este muda muito rapidamente. Neste trabalho, entre os dois momentos em que ele foi elaborado, há diferenças importantes. Para mostrar-se útil, o mapeamento deve sofrer revisões periódicas.

O ponto forte do mapeamento de pressões é que ele torna clara a dimensão da movimentação dos participantes do mercado. Hoje a empresa $\mathrm{X}$ estuda a formação de aliança estratégica com outra empresa visando se fortalecer.

Para manter-se competitiva, a empresa $\mathrm{X}$ aceitou a sugestão do estudo anterior e utilizou-se basicamente do desenvolvimento de seu capital social, o que aumentou consideravelmente seu fluxo de importação de conhecimento externo.

É importante, neste ponto, fazer uma análise crítica desta abordagem utilizada, ou seja, para a manutenção da competitividade da empresa, promover o aumento no nível de conhecimento aplicável à gestão de operações por meio do capital social, dos relacionamentos com agentes externos à organização.

Um ponto muito forte da abordagem foi a rapidez em se absorver conhecimento tácito, que comparado aos meios normais, baseados unicamente em recursos internos, não se obteria. Houve uma redução importante do gap tecnológico que havia entre a empresa $\mathrm{X}$ e a líder, a ponto de mudar a maneira de pensar da direção da empresa X. A aquisição de conhecimento externo, que antes era vista na empresa com certa antipatia, pois era um sinal de que lhes faltava capacitação técnica, hoje é vista com outros olhos, desprovida de antigos preconceitos.

Como ponto fraco tem-se o risco alto em adquirir-se informação que não atenda à expectativa, que não alcance a qualidade exigida. No caso da empresa X, o desempenho econômico alcançado pela transferência de conhecimento de agentes externos, principalmente na área de desenvolvimento de produtos, foi abaixo do esperado. Ficou confirmado que a utilização do capital social não dispensa o investimento em $\mathrm{P} \& \mathrm{D}$.

Constatou-se a necessidade de formação contínua do pessoal interno. Sem que este esteja preparado para absorver novos conhecimentos, trazer agentes externos para prover conhecimento pode significar um gasto inútil.

Confirmou-se que o aprendizado contínuo é o elemento motor do modelo dinâmico de estratégia-competência. Uma das maneiras de promover o aumento do conhecimento pode ser a utilização do capital social.

\section{Referências Bibliográficas}

ANAND, V.; GLICK, W. H.; MANZ, C. C. Thriving on the knowledge of outsiders: Tapping organizational social capital. Academy Management Executive, v. 16, n. 1, p. 87-101, february 2002.

BEAL, R. M. Competing Effectively: Environmental Scanning, Competitive Strategy, and Organizational Performance in Small Manufacturing Firms. Journal of Small Business Management, v. 38, n. 1, p. 27-47, january, 2000.

COURTNEY, H.; KIRKLAND, J.; VIGUERIE, P. Strategy Under Uncertainty. Harvard Business Review, p. 67-79, november/december 1997.

D'AVENI, R. A. Competitive pressure systems - mapping and managing multimarket contact. MIT Sloan Management Review, p. 39-49, Fall 2002.

FLEURY, A. C. C.; FLEURY, M. T. L. Competitive strategies and core competencies: perspectives for the internationalization on industry in Brazil. Integrated Manufacturing Systems, Bradford, v. 14, n. 1, p. 16-25, 2003.

GLOBALIZAÇÃO. In Dicionário Houaiss da língua portuguesa. Rio de Janeiro: Objetiva, 2004. Disponível em: <http://v.houaiss.uol.com.br>. Acesso em: 6 dez. 2004.

HAYES, R.; PISANO, G.; UPTON, D.; WHEELWRIGHT, S. Operations, Strategy, and Technology: Pursuing the Competitive Edge. Hoboken: John Wiley \& Sons, 2005.

HITT, M. A.; IRELAND, R. D. The essence of strategic leadership: Managing human and social capital. Journal of Leadership \& Organizational Studies, v. 9, n. 1, p. 3-14, Summer 2002.

KNIGHT, G. Entrepreneurship and Marketing Strategy: The SME Under Globalization. Journal of International Marketing, v. 8, n. 2, p. 12-32, 2000.

LANE, D.; MAXFIELD, R. Foresight, Complexity and Strategy, 1995. Disponível em: <http://www.santafe. edu>. Acesso em: 23 out. 2003.

ORGANISATION for ECONOMIC CO-OPERATION and DEVELOPMENT. The Bologna Charter on SME Policies, 2000. Disponível em: <http://www.oecd.org>. Acesso em 28 jun. 2005.

PORTER, M. A Vantagem Competitiva das Nações. Rio de Janeiro: Campus, 1993. 


\title{
SURVIVAL STRATEGIES FOR SMES IN GLOBAL ENVIRONMENTS: A CASE STUDY IN THE ELECTRIC AND ELECTRONIC SECTOR
}

\begin{abstract}
Globalization has led to increasing levels of rivalry and competitive pressure among competitors acting in the same markets and geographical regions. Nonetheless, small and medium enterprises are becoming critical players in national economies and worldwide businesses. However, little is known about the operations strategies these SMEs employ to face the pressures of globalization. In Brazil, the growing market upheaval and uncertainty has been aggravated by the increasing number of mergers with and acquisitions by global organizations and companies operating in the country. In this context, companies that are knowledgeable about the environment in which they operate can take proactive action and influence the system's evolution. This article discusses the relations between competitive business environments, perceived uncertainties, threats and opportunities from the standpoint of SMEs. A case study of a medium size company, dubbed $X$, is described here. This company enjoyed a stable situation in the market for about eleven years, ranking second in its area in the domestic market, until the domestic leader company was acquired by a leading global corporation. This article lists and discusses suggestions that helped the company remain competitive despite its paucity of financial and human resources.
\end{abstract}

Keywords: small and medium enterprises, globalization, operations strategy, social capital. 